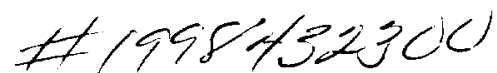

\title{
Influence of Subpixel-Scale Cloud-Top Structure on Reflectances from Overcast Stratiform Cloud Layers
}

\author{
NORMAN G. LOEB* \\ College of Oceanic and Atmospheric Sciences, Oregon State University, Corvallis, Oregon \\ TAMÁS VÁRNAI \\ Institute of Atmospheric Phssics, The University of Arizona. Tucson. Arizona \\ DAVID M. WINKER \\ Almospheric Sciences Division. NASA/Langley Research Center. Hampton. Virginia
}

(Manuscript received 24 February 1997, in final form 4 February 1998)

\section{ABSTRACT}

\begin{abstract}
Recent observational studies have shown that satellite retrievals of cloud optical depth based on plane-parallel model theory suffer from systematic biases that depend on viewing geometry, even when observations are restricted to overcast marine stratus layers, arguably the closest to plane parallel in nature. At moderate to low sun elevations, the plane-parallel model significantly overestimates the reflectance dependence on view angle in the forward-sciltering direction but show's a similar dependence in the backscattering direction. Theoretical simulations are performed that show that the likely cause for this discrepancy is because the plane-parallel model assumption does not account for subpixel-scale variations in cloud-top height (i.e., "cloud bumps"). Monte Carlo simulations comparing 1D model radiances to radiances from overcast cloud fields with 1) cloud-1op height variations but constant cloud volume extinction. 2) flat tops but horizontal variations in cloud volume extinction. and 3) variations in both cloud-top height and cloud extinction are performed over a $\approx 4 \mathrm{~km} \times 4$ $\mathrm{km}$ domain (roughly the size of an individual GAC AVHRR pixel). The comparisons show that when cloudtop height variations are included, departures from 1D theory are remarkably similar (qualitatively) to those obtained observationally. In contrast, when clouds are assumed flat and only cloud extinction is variable, reflectance differences are much smaller and do not show any view-angle dependence. When both cloud-top height and eloud extinction variations are included, however. large increases in cloud extinction variability can enhance reflectance differences. The reason 3D-1D reflectance differences are more sensitive to cloud-top height variations in the forward-scattering direction (at moderate to low sun elevations) is because photons leaving the cloud field in that direction experience fewer scattering events (low-order scattering) and are restricted to the topmost portions of the cloud. While reflectance deviations from ID theory are much larger for bumpy clouds than for flat clouds with variable cloud extinction. differences in cloud albedo are comparable for these two cases.
\end{abstract}

\section{Introduction}

Inhomogeneities in cloud properties can have a significant influence on satellite-measured radiances and flux estimates, particularly in the visible part of the spectrum. Cloud inhomogeneities can occur because of variations in cloud liquid water path le.g., variability at scales smaller than or comparable to individual cloud

\footnotetext{
* Current atfiliation: Center for Atmospheric Sciences, Hampton University, Hampton, Virginia.
}

Corresponding author address: Dr. Norman G. Loeb. Atmospheric Sciences Division, NASA/Langley Research Center. Mail Stop 420. Hampton, VA 23681.

E-mail: n.g.loeb@larc.nasa.gov elements (within-cloud variability), sharp discontinuities due to clear-sky breaks (broken clouds)], or because of variations in cloud geometry (e.g., nonflat cloud tops, cloud sides). The degree to which satellite measurements are influenced by cloud inhomogeneities depends on the spatial resolution of the instrument, the sunearth-satellite viewing geometry, and whether the observations are analyzed at the local pixel scale or over larger regions by averaging pixel-level values. Given that the standard approach used in cloud remote sensing applications and climate models relies on the planeparallel model approximation, which assumes that clouds are one-dimensional and therefore horizontally homogeneous, it is paramount that any biases or uncertainties due to cloud inhomogeneity be identified.

There is much evidence that variations in marine stratus cloud liquid water have a strong radiative effect. 

Coakley (1991) showed that, on average, visible reflectivities from broken marine stratocumulus are $\approx 15 \%$ $20 \%$ lower than those from uniform layered clouds taken from the same layers. Cahalan et al. (1994) showed that within-cloud variations in stratocumulus cloud liquid water can cause albedos to be lower than plane-parallel values by $\approx 15 \%$ over mesoscale regions. Cahalan et al. (1994) note, however, that the bias is significantly reduced when the independent pixel approximation (IPA) is used; IPA estimates the mesoscale-average albedo over a region by accounting for its optical depth probability density in 1D model calculations (thus ignoring horizontal radiative transport). Model simulations by Marshak et al. (1995) show that the IPA is applicable only for pixels larger than $\approx 200 \mathrm{~m}$ (corresponding to the "radiative smoothing" scale) because neglect of horizontal photon transport at smaller scales leads to significant instantaneous errors in albedo.

Based on these studies, one might therefore expect biases in cloud retrievals to be small when the IPA method is applied over extensive marine stratus and satellite pixel size is larger than the radiative smoothing scale. A recent study by Loeb and Coakley (1998 hereafter LC98) shows that this is not the case. LC98 used one month of global area coverage (GAC) Advanced Very High Resolution Radiometer (AVHRR) visible measurements [pixel size $\approx 4 \mathrm{~km} \times 4 \mathrm{~km}$ ] to examine the consistency of plane-parallel model retrievals of cloud optical depth from overcast stratiform layers off the coasts of California, Angola, and Peru. They showed that cloud optical depth distributions inferred at the pixel level from plane-parallel theory suffer from a systematic view angle-dependent bias in the forward-scattering direction at moderate to low sun elevations and a strong solar zenith angle-dependent bias at all view angles, particularly at low sun elevations. The latter conclusion was also observed in Loeb and Davies (1996) using coarser-resolution Earth Radiation Budget Experiment (ERBE) scanner measurements over the tropical oceans.

Given that LC98 restricted the analysis to uniform overcast stratus layers, thereby constraining the comparisons to cloud systems that arguably are the closest to plane parallel in nature, it is not immediately clear why systematic biases in cloud optical depth retrievals were observed. Based on previous theoretical studies (e.g., Davies 1978; Welch and Wielicki 1984; Barker 1994; Loeb et al. 1997) and on preliminary Monte Carlo simulations, LC98 proposed that one reason may be because the IPA assumes that clouds are flat at subpixel scales. A glance out the window of an aircraft clearly shows that even overcast marine stratus layers can have highly irregular cloud tops (or "bumpiness"). However, marine stratus also have large variations in cloud liquid water (or cloud extinction) (Cahalan and Snider 1989; Barker 1992; Davis et al. 1997). Since the IPA is essentially a plane-parallel calculation at the pixel scale, subpixel-scale variability in cloud liquid water may also be important, possibly introducing a "subpixel" planeparallel model reflectance bias (Cahalan et al. 1994).

Unfortunately, these effects are difficult to examine observationally. The present study therefore adopts a theoretical approach to investigate how spatial variations in cloud-top height and cloud extinction affect reflectances and albedos from overcast layers over a domain size comparable to an individual GAC AVHRR pixel [ $\approx 4 \mathrm{~km} \times 4 \mathrm{~km}$ ]. Monte Carlo simulations comparing ID model reflectances with those from overcast 3D cloud fields having 1) cloud-top height variations but constant cloud volume extinction, 2) flat tops but horizontal variations in cloud volume extinction, and 3) variations in both cloud-top height and cloud extinction are considered.

\section{Methodology}

\section{a. Monte Carlo simulations}

Monte Carlo simulations are performed using the model of Várnai (1996). The model assumes periodic boundary conditions, so that photons leaving one side of a cloud field boundary come back at the opposite side. In each simulation, $10^{\circ}$ photons are used. The angular bin interval is 0.1 for the cosine of the observer zenith angle and $30^{\circ}$ for the relative azimuth, which gives a reflectance uncertainty of $\leqslant 1 \%$. Simulations are performed at solar zenith angles $\left(\theta_{0}\right)$ of $30^{\circ}, 65^{\circ}$, and $80^{\circ}$ for domain cloud optical depths $\left(\tau_{d}\right)$ of 5 and 10 , and each cloud field is treated as a single realization. The cloud phase function is defined at a wavelength of $0.865 \mu \mathrm{m}$ and is calculated based on Mie theory using the $\mathrm{Sc}_{\text {top }}$ cloud drop size distribution of Welch et al. (1980). In all cases, a single scattering albedo $\left(\omega_{10}\right)$ of 1.0 is assumed. Atmospheric effects above or below the cloud fields and reflection by the underlying surface (assumed to be ocean) are not considered. Reflectance is defined as

$$
R\left(\mu, \mu_{0}, \phi\right)=\frac{\pi I\left(\mu, \mu_{0}, \phi\right)}{\mu_{0} F}
$$

where $I$ is the pixel radiance ( $\mathrm{W} \mathrm{m}^{2} \mathrm{sr}^{1} \mu \mathrm{m}^{1}$ ), $F$ the solar irradiance $\left(\mathrm{W} \mathrm{m}^{2} \mu \mathrm{m}^{-1}\right), \mu$ the cosine of observer zenith angle, $\mu_{i}$ the cosine of solar zenith angle, and $\phi$ is the azimuth angle relative to solar plane $\left(\phi=0^{\circ}\right.$ corresponds to forward scattering).

\section{b. Cloud fields}

1) VARIABLE CLOUD-TOP HEIGHT AND CONSTANT CLOUD EXTINCTION

A stochastic cloud model (Barker and Davies 1992a; Várnai 1996) is used to generate cloud fields with cloudtop height variations. The cloud fields are characterized by continuous power spectra with a structure represented by the slope of the wavenumber spectrum of 
TABL.F I. Scaling exponents $\left(s_{1}\right.$ and $\left.s_{2}\right)$ and scale break wavenumber $\left(k_{\mathrm{b}}\right)$ used in Eq. (2) to generate the stochastic cloud fields considered in this study. The scale break of $k_{\mathrm{br}}=6 / \mathrm{Lkm}$ ' corresponds to a length scale of $\approx 728 \mathrm{~m}$. Here $L$ is the domain size $(\approx 4.4 \mathrm{~km})$.

\begin{tabular}{lccc}
\hline \hline Cloud tield & $s_{1}$ & $k_{\mathrm{by}} L$ & $s_{2}$ \\
\hline STOCHA & 1 & 6 & 1.6 \\
STOCHB & 1 & 6 & 3.6 \\
STOCHC & 1 & 6 & 6.0 \\
\hline
\end{tabular}

cloud thickness. The ensemble averaged one-dimensional spectra scale according to the following:

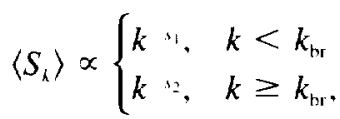

where $\left\langle S_{k}\right\rangle$ is the averaged ID power spectrum, $k$ is the wavenumber $\left(\mathrm{km}^{\mathrm{l}}\right), k_{\mathrm{br}}$ is the wavenumber at the scale break. and $s_{1}$ and $s_{2}$ are the scaling exponents for large $\left(k<k_{\mathrm{b},}\right)$ and small $\left(k \geq k_{\mathrm{b} r}\right)$ spatial scales, respectively. Small values of $s_{2}$ produce cloud fields with many smallscale variations ( $s_{2}=0$ corresponds to white noise), while larger values produce smoother fields. Such scale breaks have been observed in lidar measurements of cloud-top height above marine stratocumulus (Boers et al. 1988). The measurements show a $k^{5 / 3}$ behavior at scales smaller than $\approx 1 \mathrm{~km}$ and $k$ ' at larger scales. Scale breaks have also been observed in Landsat reflectivities by Cahalan and Snider ( 1989 ) between $\approx 200$ and 400 $m$ and in AVHRR observations (both in the visible and infrared) by Barker and Davies (1992b) and Oreopoulos (1996) between $\approx 5$ and $7 \mathrm{~km}$. The Landsat scale break is believed to be due to horizontal photon transport or radiative smoothing (Marshak et al. 1995; Davis et al. 1997), while the cause for the AVHRR scale break is unclear at the present time. Here, the scale break is fixed at $k_{\mathrm{br}}=6 / L \mathrm{~km}{ }^{1}$, where $L$ corresponds to the domain size. Cloud fields are defined over a $128 \times 128$ horizontal grid with gridpoint spacing of $34.4 \mathrm{~m}$, corresponding to a domain size of $\approx 4.4 \mathrm{~km} \times 4.4 \mathrm{~km}$. Consequently, $k_{\mathrm{hr}}=1.373 \mathrm{~km}$ ', and the length scale where the scale break occurs is $\approx 0.728 \mathrm{~km}$ [which is close to the $1 \mathrm{~km}$ scale-break observed by Boers et al. (1988)]. In simulations where cloud extinction $(\beta)$ variability is not accounted for, a value of $\beta=30 \mathrm{~km}^{-1}$ is assumed.

To examine a range of cloud-top structures, three very different scalings are considered (Table 1). These correspond to clouds whose tops range from being highly erratic at small scales ( $\leq 728 \mathrm{~m}$ ) (STOCHA) to fairly smooth (STOCHC). At larger scales $(>728 \mathrm{~m}$ ), the same scaling $\left(s_{1}=1\right)$ is assumed in all cases. While the stochastic model provides information on the horizontal spatial variability in cloud-top height, there is no information on the actual vertical extent of the cloud bumps. To examine a range of possibilities, cloud-top heights are specified such that the domain standard deviation lies between $\approx 10$ and $100 \mathrm{~m}$. This range is consistent with recent Lidar In-Space Technology Experi-
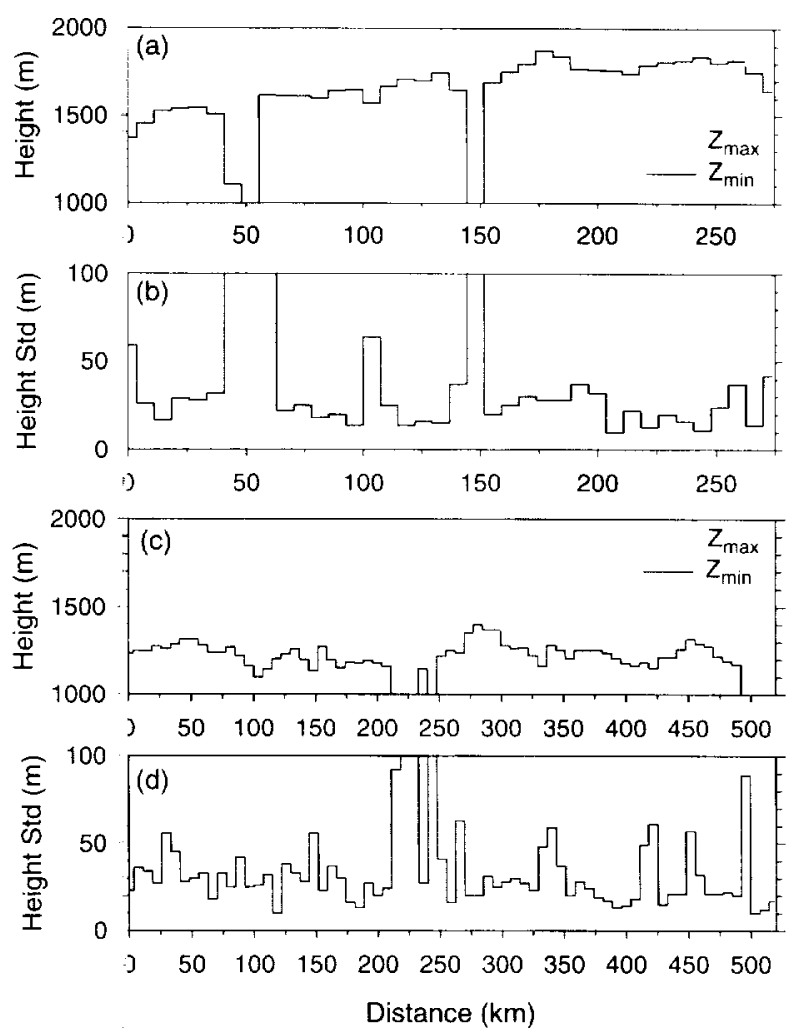

FiG. 1. Cloud-top height maxima, minima, and standard deviations for region; of extensive stratus measured by the LITE for a portion of an orbil on 14 September 1994. (a). (b) Measurements off the coast of Califor ia $\left(36.3^{\circ} \mathrm{N}, 132.4^{\circ} \mathrm{W}\right.$ to $34.5^{\circ} \mathrm{N}, 130.5^{\circ} \mathrm{W}$ ) (c), (d) measurements from the equatorial Pacitic Ocean $\left(2.3^{\circ} \mathrm{N}, 108.2^{\circ} \mathrm{W}\right.$ to $\left.1.7^{\circ} \mathrm{S}, 10 \mathrm{t} .0^{\circ} \mathrm{W}\right)$.

ment (LITE) (Winker et al. 1996) measurements from extensive stratus layers, as illustrated in Fig. 1. The LITE cloud-top height maxima $\left(Z_{\text {mux }}\right)$, minima $\left(Z_{\text {min }}\right)$, and star dard deviations in Fig. 1 were obtained at $1-s$ interval: along the orbital path from ten $290-\mathrm{m}$ resolution sı bsamples $740 \mathrm{~m}$ apart (the range resolution of the LIT]: measurements is $15 \mathrm{~m}$ ). As shown, cloud-top height $\mathrm{s}$ andard deviations range from $\approx 10$ to $\approx 100 \mathrm{~m}$ (standar 1 deviations greater that $200 \mathrm{~m}$ are due to clearsky brecks in cloud field), and differences between the maximu $n$ and minimum heights $\left(Z_{\mathrm{max}}-Z_{\mathrm{min}}\right)$ typically range fr $\mathrm{m} \approx 30$ to $\approx 250 \mathrm{~m}$. Similar results were observed t y Boers et al. (1988) using high-resolution aircraft lid ir measurements over marine stratocumulus.

Table 2 provides a summary of the geometric characteristi: $s$ of the cloud fields for $\tau_{d}=10$. For each stochast $\mathrm{c}$ cloud model in Table 1 , four cloud fields with cloud-top height standard deviations $\left(\sigma_{\zeta}\right)$ between $\approx 10$ and $\approx 1,00 \mathrm{~m}$ are defined. Note that since cloud-base height remains constant (i.e., at $Z=0 \mathrm{~m}$ ), cloud-top height and cloud thickness at each grid point are identical. Fi;zure 2 shows an example of three cloud fields correspinding to the STOCHA, STOCHB, and STOCHC scalings (Table 1) with $\sigma$,'s of $42.9,44.6$, and 
TABLE 2. Geometric characteristics of the stochastic cloud fields considered in this study for $\tau_{\alpha}=10$. Here $Z_{\text {nir }}$ and $Z_{\text {was }}$ are the minimum and maximum cloud-top heights $(\mathrm{m})$. respectively: $\bar{W}$ is the domain average horizontal width of the cloud bumps along $\bar{Z} ; \overline{\mathrm{H}}$ is the domain average vertical extent of the cloud bumps relative to $\bar{Z} ;$ and $\overline{\mathrm{AR}}$ is the mean cloud bump aspect ratio determined from the aspect ratio of individual cloud bumps. Individual cloud bump aspect ratios are defined as the ratio of the vertical extent of a cloud bump above $\bar{Z}$ to its a horizontal width along $\bar{Z}$. Also, $\sigma$ is the cloud-top height standard deviation over the domain $(\mathrm{m}) ; v_{\tau, d}=$ domain cloud optical depth standard deviation, assuming a constant cloud thickness of $333.3 \mathrm{~m}$.

\begin{tabular}{llrlrrrrr}
\hline \hline $\begin{array}{c}\text { Cloud } \\
\text { field }\end{array}$ & & $Z_{\min }$ & $Z_{\max }$ & \multicolumn{1}{c}{$\overline{\mathrm{W}}$} & $\overline{\mathrm{H}}$ & $\overline{\mathrm{A}} \overline{\mathrm{R}}$ & $\sigma_{i}$ & $\sigma_{\mathrm{Td}}$ \\
\hline STOCHA & $a$ & 300.5 & 366.5 & 91.1 & 8.2 & 0.16 & 8.6 & 0.26 \\
& $b$ & 267.7 & 400.0 & 91.1 & 16.4 & 0.32 & 17.2 & 0.52 \\
& $c$ & 169.2 & 499.2 & 91.1 & 40.9 & 0.80 & 42.9 & 1.29 \\
& $d$ & 5.0 & 665.0 & 91.1 & 81.9 & 1.60 & 85.7 & 2.57 \\
STOCHB & $a$ & 300.5 & 372.5 & 272.3 & 8.1 & 0.04 & 8.9 & 0.27 \\
& $b$ & 267.7 & 411.7 & 272.3 & 16.2 & 0.08 & 17.8 & 0.53 \\
& $c$ & 169.2 & 529.2 & 272.3 & 40.5 & 0.20 & 44.6 & 1.34 \\
& $d$ & 5.1 & 725.1 & 272.3 & 81.1 & 0.41 & 89.1 & 2.67 \\
STOCHC & $a$ & 300.5 & 373.5 & 504.5 & 10.6 & 0.02 & 9.6 & 0.29 \\
& $b$ & 267.7 & 413.7 & 504.5 & 21.3 & 0.05 & 19.2 & 0.58 \\
& $c$ & 169.2 & 534.2 & 504.5 & 53.2 & 0.12 & 47.9 & 1.44 \\
& $d$ & 5.0 & 735.0 & 504.5 & 106.4 & 0.24 & 95.8 & 2.87 \\
\hline
\end{tabular}

$47.9 \mathrm{~m}$, respectively, and a domain average cloud-top height $(\bar{Z})$ of $333.3 \mathrm{~m}$. Horizontal cross sections of cloud-top height through the center of each cloud field in Table 2 are provided in Figs. 3a-c. As shown, all cloud fields share the same spatial variability at large scales but have a very different structure at smaller scales (i.e., at scales $\leq 728 \mathrm{~m}$ ).

While it is unlikely that these cloud fields represent the complete range of variability observed in nature, they do serve as a convenient starting point for studying the role of cloud-top geometry at subpixel scales and arguably are a significant improvement over the simpler cloud geometries used in earlier Monte Carlo studies (e.g., cubes, cylinders, etc.).

\section{2) FLAT TOPS AND VARIABLE CLOUd EXTINCTION}

To examine how variations in cloud volume extinction affect reflectance, simulations involving flat clouds possessing horizontal variations in $\beta$ are performed. Such cloud fields have frequently been used to study the influence of cloud liquid water variations over mesoscale regions. The main difficulty in specifying these cloud fields is in establishing what constitutes "realistic" $\beta$ variations. Since biases increase with $\beta$ variability, it is crucial that reasonable $\beta$ fields be used. Cahalan et al. (1994) and Marshak et al. (1995) rely on a two-parameter multiplicative fractal bounded cascade model and specify model parameters using liquid water path (LWP) measurements from marine stratocumulus during the First ISCCP (International Satellite Cloud Climatology Project) Regional Experiment (FIRE) (Cahalan and Snider 1989). Unfortunately, their "fractal

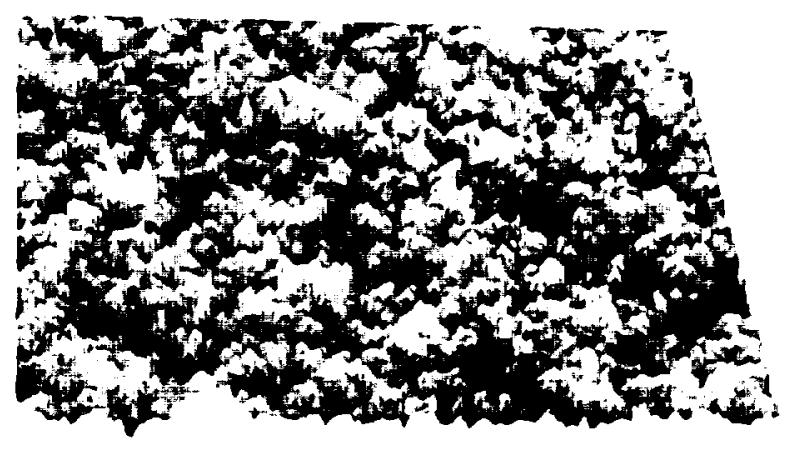

(a)

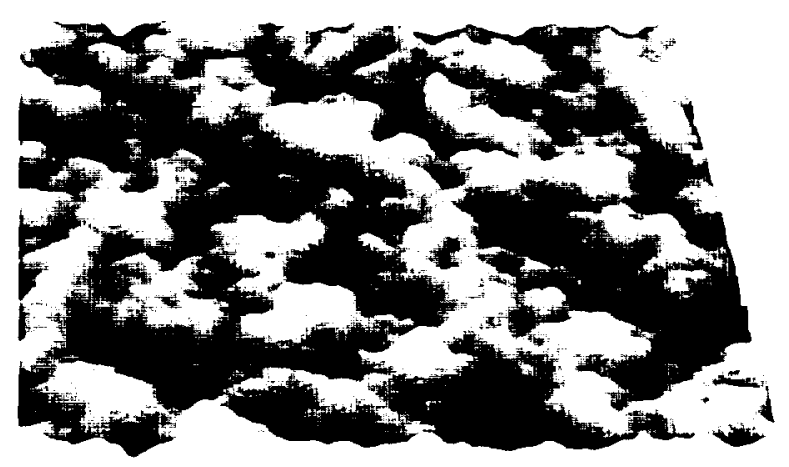

(b)

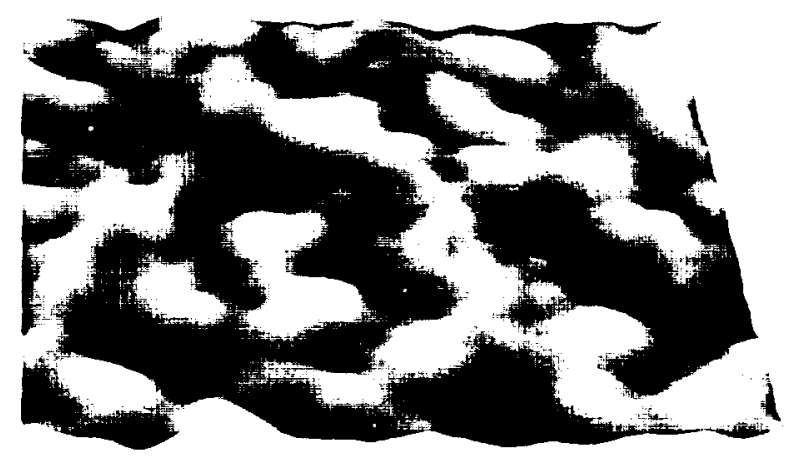

(c)

FiG. 2. Schematic illustrating 3D structure for (a) STOCHA $\left(\sigma_{1}=\right.$ $43 \mathrm{~m})$, (b) STOCHB $(\sigma,=45 \mathrm{~m})$, (c) STOCHC $\left(\sigma_{l}=48 \mathrm{~m}\right)$ cloud fields.

parameter," which determines the degree of variability in the $\beta$ field, is inferred from 18 days of LWP distributions and thus likely overestimates the variability in $\beta$ over a typical overcast $\approx 4 \mathrm{~km} \times 4 \mathrm{~km}$ region. An alternate method of inferring $\beta$ fields is from satellite retrievals of cloud optical depth (Barker and Liu 1995; Chambers et al. 1997). The main advantage is the availability of observations compared to in situ measurements, but the disadvantage is that cloud thickness needs 

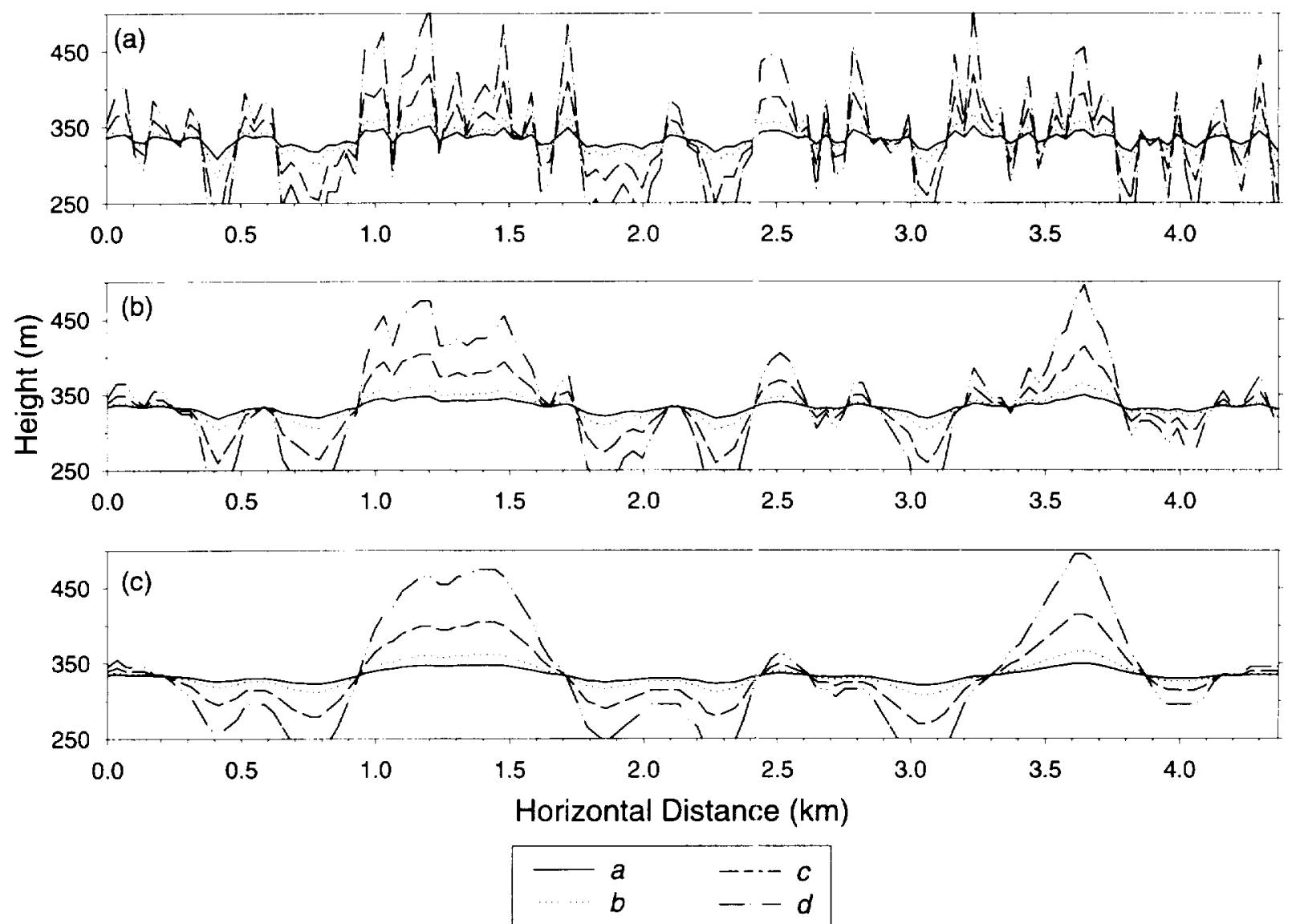

FIG. 3. Horizontal cross sections of cloud-top height across the center of (a) iTOCHA, (b) STOCHB, and (c) STOCHC cloud fields defined in Table 2.

to be estimated and cloud optical depths may suffer from large instantaneous errors (Marshak et al. 1995).

Despite these limitations, variable $\beta$ fields in the present study are inferred using Landsat observations from overcast marine stratus layers off the coast of California. The variable $\beta$ fields are defined over $\approx 4 \mathrm{~km} \times 4 \mathrm{~km}$ subregions derived from Landsat cloud optical depth retrievals (at $28-\mathrm{m}$ resolution) generously provided by the authors in Barker et al. (1996) for three $58 \mathrm{~km} \times$ $58 \mathrm{~km}$ Landsat images (scenes A9, A10, and A11 in their Table 1). In order to maximize the influence of the $\beta$ fields on reflectance, only the most variable $\approx(4 \mathrm{~km})^{2}$

TABLF 3. Cloud extinction and cloud optical depth statistics for flat clouds with variable extinction. Here $\beta_{\text {mm }}=$ minimum volume ex tinction coefficient $\left(\mathrm{km}\right.$ ). $\beta_{\mathrm{tun}}=$ maximum volume extinction coefficient $(\mathrm{km})$ ). $\sigma_{\mathrm{a}}=$ volume extinction coefficient standard deviation $\left(\mathrm{km}{ }^{\mathrm{1}}\right), \sigma_{\mathrm{t} t}=$ domain cloud optical depth standard deviation, assuming a constant cloud thickness of $333.3 \mathrm{~m}$.

\begin{tabular}{lrrrr}
\hline \hline Cloud field & $\beta_{\text {mam }}$ & $\beta_{\text {mas }}$ & $\sigma_{\beta}$ & $\sigma_{\text {td }}$ \\
\hline LSATA9 & 0.69 & 59.9 & 11.2 & 3.74 \\
LSATA10 & 2.82 & 141.7 & 16.3 & 5.44 \\
LSATA1 & 8.66 & 74.5 & 9.9 & 3.30 \\
\hline
\end{tabular}

subregions from each image, as determined from the maximum cloud optical depth standard deviation-tomean ritio, are considered. After renormalizing cloud optical depths from each subregion so that the mean domain optical depth is equal to $\tau_{d}$, pixel-level $\beta$ 's are determi red assuming a constant cloud thickness (e.g., $\bar{Z}=333.3 \mathrm{~m}$ for $\tau_{d}=10 ; \bar{Z}=166.7 \mathrm{~m}$ for $\tau_{d}=5$ ). Means ind standard deviations in $\beta$ and $\tau_{d}$ corresponding to these cloud fields are provided in Table 3 . Compared $t$, the stochastic cloud fields possessing only cloud-t $p$ height variations (Table 2 ), the $\beta$ fields are much n ore variable; $\sigma_{\tau}$, values for the variable $\beta$ fields (Table $:$ ) are typically three times larger than stochastic cloud field values (at least for $\sigma_{Z}<50 \mathrm{~m}$ ).

\section{3) V IRIABLE CLOUD-TOP HEIGHT AND VARIABLE CI OUD EXTINCTION}

In real clouds, both cloud-top height and cloud extinction may vary. Minnis et al. (1992) used surfacebased ceilometer and acoustic sounder measurements along $w$ ith satellite-derived cloud optical depth retrievals [from the Geostationary Operational Environment 
TABLE 4. Cloud-top height, extinction, and optical depth statistics for cloud fields with both variable cloud-top height and variable cloud extinction. The domain cloud optical depth $\left(\tau_{d}\right)$ is 10 in all cases

\begin{tabular}{cccccc}
\hline \hline Cloud tield & $\bar{Z}$ & $\sigma$, & $\beta$ & $\sigma_{\beta}$ & $\sigma_{\mathrm{r} d}$ \\
\hline STOCHA_V1 & 330.3 & 44.5 & 29.7 & 4.0 & 2.6 \\
STOCHA_V2 & 330.3 & 44.5 & 28.6 & 10.7 & 4.9 \\
STOCHB_V1 & 330.0 & 46.3 & 29.7 & 4.2 & 2.7 \\
STOCHB_V2 & 330.0 & 46.3 & 28.7 & 11.2 & 5.1 \\
STOCHC_V1 & 329.5 & 50.2 & 29.7 & 4.5 & 2.9 \\
STOCHC_V2 & 329.5 & 50.2 & 28.8 & 12.1 & 5.6 \\
\hline
\end{tabular}

Satellite (GOES)] during FIRE to show that geometric cloud thickness is reasonably well correlated with the square root of cloud optical thickness. Chambers et al. (1997) subsequently used this relationship to generate cloud fields possessing $2 \mathrm{D}$ variations in cloud extinction and cloud thickness. Here, a similar approach is adopted for one set of cloud fields. To examine how drastic changes in the $\beta$ field affect reflectances, a second set of cloud fields is considered that has the same cloudtop height variability as the first set but a much more variable $\beta$ field.

Starting with cloud optical depths for the most bumpy of the STOCHA, STOCHB, and STOCHC cloud fields ( $d$ cases in Table 2), cloud-top heights are redefined as follows:

$$
Z_{i j}^{\prime}=\kappa \sqrt{\tau_{i j}},
$$

where $\tau_{i j}$ is the cloud optical depth at grid point $(i, j)$, and $\kappa$ is a constant. Here, $\kappa$ is set to $105.4082 \mathrm{~m}$ for all cloud fields with $\tau_{d}=10$ to ensure that $\bar{Z}_{t}^{\prime} \approx 333$ $\mathrm{m}$. Next, two very different methods of determining cloud volume extinction coefficients at each grid point $\left(\beta_{i j}\right)$ are used. The first is given by

$$
\beta_{1}=\frac{\tau}{Z^{\prime}},
$$

where the subscripts $i j$ were dropped for convenience. A summary of the cloud fields defined by Eqs. (3) and (4) is provided in Table 4 (STOCHA_V1, STOCHB_V1;
STOCHC_V1), and a cross section through one of these cases (STOCHB) is shown in Fig. 4.

In order to examine how drastic changes in cloud extinction affect cloud reflectances, a second set of cloud fields is constructed that uses the same $Z_{i j}^{\prime}$ as inferred from Eq. (3) but a much more variable $\beta$ field. Specifically, cloud extinction is rescaled using the following expression:

$$
\beta_{2}=\varepsilon \beta_{1}^{\prime} Z^{\prime},
$$

where $\varepsilon$ is a constant that ensures that the new domain cloud optical depth $\left(=\left\langle\beta_{2} Z^{\prime}\right\rangle\right)$ is the same as that for cloud fields defined by Eqs. (3) and (4) (e.g., for $\tau_{d}=$ $10, \varepsilon=10.75$ ). Figure 4 shows horizontal cross sections for cloud fields with cloud-top heights and extinction coefficients inferred from Eqs. (3) and (5) ("STOCHB_V2") for $\tau_{d}=10$. The main difference between the V1 and V2 cloud fields is that in the latter $\beta$ (and therefore optical depth) is enhanced in the peaks of the height field and reduced in the valleys. As shown in Table 4, cloud fields with $\beta$ inferred from Eq. (5) are much more variable. Note that the $\beta$ field defined in Eq. (5) is introduced simply to examine the influence of large changes in cloud extinction when cloud bumps are present and is not necessarily representative of $\beta$ variability in real clouds.

\section{Results}

\section{a. Reflectance differences}

Figures 5a,b show bidirectional reflectances for the STOCHC variable cloud-top height field with $\sigma_{z}=48$ $\mathrm{m}$ (Fig. 2c) and the plane-parallel model for $\tau_{d}=10$ at $\theta_{0}=65^{\circ}$. While the overall characteristics in reflectance are quite similar for these two cases, the planeparallel model values are noticeably larger in the forward-scattering direction, by as much as $\approx 15 \%$ (relative difference). Differences are much smaller $(\leqslant 5 \%)$ in the backscattering direction. Figures $6 a-c$ show relative reflectance differences between 3D and 1D model cal-

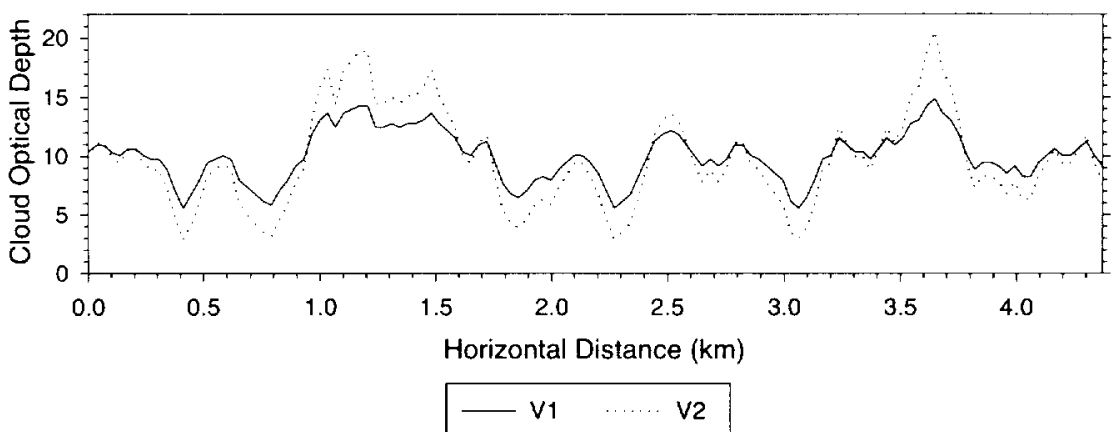

FIG. 4. Cloud optical depth horizontal cross sections for cloud fields with variations in both cloud-top height and cloud extinction. Here Vl corresponds to cloud-top height and cloud extinction ficlds from Eqs. (3) and (4): V2 corresponds to cloud fields inferred from Eqs. (3) and (5). 


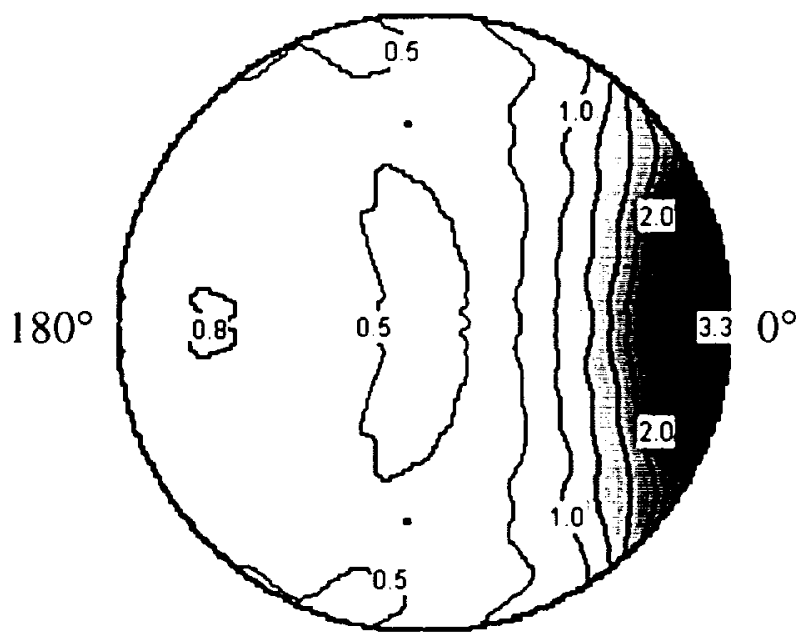

(a)
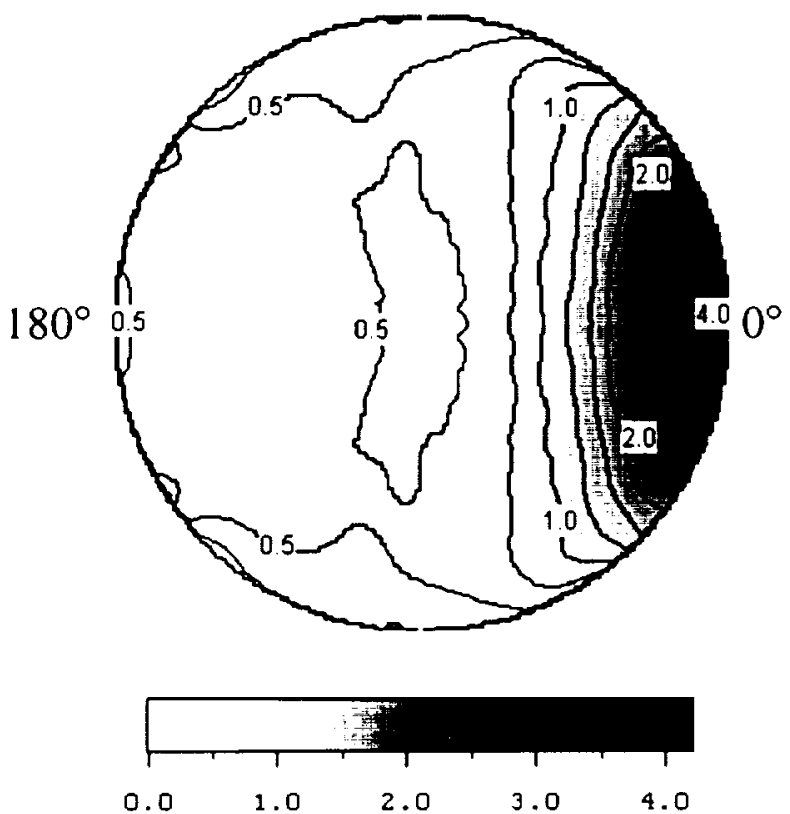

(b)

Fici. 5. Bidirectional reflectance for $\tau_{d}=10$ and $\theta_{11}=65^{\circ}$ from (a) STOCHC $\left(\sigma_{r}=48 \mathrm{~m}\right)$ and (b) the plane-parallel model. Here $\mu$ increatses with radial distance from the center of the circle and $\phi$ changes azimuthally $\left(\phi=0^{\circ}\right.$ is on the right and $\phi=180^{\circ}$ is on the left as indicated).

culations $\left\{=\left(R_{3 \mathrm{D}}-\mathbf{R}_{1 \mathrm{D}}\right) /\left[0.5\left(\mathbf{R}_{3 \mathrm{D}}+\mathbf{R}_{111}\right)\right] \times 100 \%\right\}$ for all of the variable cloud-top height fields in Table 2 [section $2 \mathrm{~b}(1)]$, in the back- $\left(\phi=150^{\circ}-170^{\circ}\right)$ and forward- $\left(\phi=10^{\circ}-30^{\circ}\right)$ scattering directions at the same $\tau_{d}$ and $\theta_{0}$ as in Fig. 5. As shown, relative reflectance differences systematically increase (in magnitude) with decreasing $\mu$ in the forward-scattering direction, reaching $\approx 30 \%$ at the most oblique view angles (Fig. 6c).
In the hackscattering direction, reflectances exceed plane-parallel values (i.e., positive relative differences), but the nagnitude of the difference is much smaller. Interestingly, relative differences in Figs. $6 \mathrm{a}-\mathrm{c}$ are highly sensitive to the spatial characteristics of the cloud bumps. For example, the largest deviations from 1D theory in the forward-scattering direction occur for the relatively smooth STOCHC cloud fields; in fact, relative differences for $\sigma_{\gamma} \approx 48 \mathrm{~m}$ (Fig. 6c) are larger (in magnitude) than even those for the highly variable STOCHA case with $\sigma_{z} \approx 86 \mathrm{~m}$ (Fig. 6a). The STOCHA clouds are extremely bumpy (Figs. $2 \mathrm{a}$ and $3 \mathrm{a}$ ) and have much larger values of $\overline{\mathrm{AR}}$ (Table 2). Here $\overline{\mathrm{AR}}$ is the mean cloud bump aspect ratio determined from the aspect ratio of individual cloud bumps (cloud bumps are defined as continuous areas where cloud-top height exceeds the domain average $\bar{Z}$ ). Reflectance differences and $\overline{\mathrm{AR}}$ values for the STOCHB cloud fields generally lie between those for STOCHA and STOCHC. Thus, reflectance differences do not necessarily increase with $\sigma_{z}$ but also depend on the horizontal extent of the cloud bumps. This relationship is examined further in section $3 c$.

Relative reflectance differences for the flat clouds with variable cloud extinction [described in Table 3: section 2b(2)] are shown in Fig. 6d. In this case, reflectance differences are much smaller in magnitude $(\leqslant 5 \%)$ and do not show any systematic dependence on $\mu$. This sccurs in spite of the much greater variability in cloud optical depth for these clouds (Table 3). Because of the nature of the plane-parallel model bias $(\mathrm{Ca}-$ halan et al. 1994), relative differences in Fig. 6d are always negative.

Figures $7 \mathrm{a}-\mathrm{c}$ show relative reflectance differences for the variable cloud-top height fields when $\theta_{0}=30^{\circ}$. Overall, relative differences are $\leqslant 10 \%$ and have a much weaker $\mu$ dependence than those at $\theta_{0}=65^{\circ}$. For the variable $B$ cloud fields (Fig. 7d), reflectance differences at $\theta_{0}=30^{\circ}$ are roughly double those at $\theta_{0}=65^{\circ}$, but magniturles remain $\leq 10 \%$. Figures $8 \mathrm{a}-\mathrm{d}$ show results for $\tau_{d}=5$ (i.e., $\bar{Z}=166.7 \mathrm{~m}$ ) at $\theta_{0}=65^{\circ}$. In this case, relative lifferences are very similar to those in Fig. 6 for $\tau_{d}=10$. Thus, deviations from $1 \mathrm{D}$ theory increase with solar zenith angle for the variable cloud-top height fields but show little sensitivity to changes in cloud optical depth.

Relati /e reflectance differences for the cloud fields possessilyg variations in both cloud-top height and cloud extinction [Table 4; section 2b(3)] are shown in Figs. $9 \mathrm{a}-\mathrm{c}$ for $\tau_{d}=10$ and $\theta_{0}=65^{\circ}$. As mentioned earlier, the only physical difference between each pair (e.g., STOCHA_V1 and STOCHA_V2) is in the 2D distribution o " cloud extinction; for the "V2" cloud fields, cloud extinction is enhanced in the peaks of the height field and reduced in the valleys, resulting in much larger $\sigma_{\beta}$. Whe $\mathrm{n}$ cloud extinction variability is enhanced in this mar ner, relative reflectance differences increase. For the STOCHA_V2 case (Fig. 9a), only a small change occurs $(\leq 3 \%$ absolute change in relative reflectance dif- 


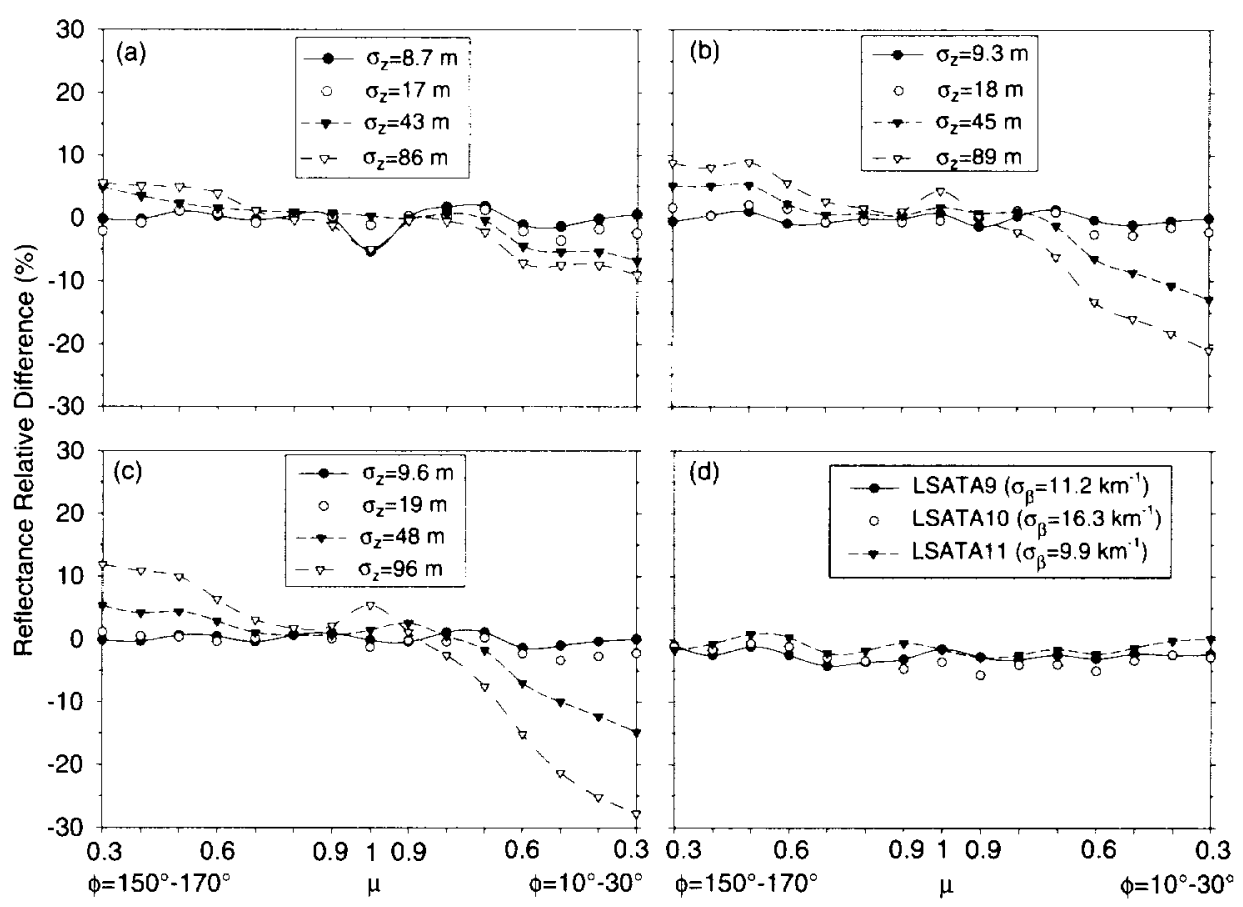

Fig. 6. Relative difference in reflectance between 3D cloud fields and plane-parallel model calculations for $\tau_{i d}=10$ and $\theta_{i}=65^{\circ}$. (a) STOCHA, (b) STOCHB, (c) STOCHC, (d) constant cloud-top height with $\beta$ defined from Landsat observations.

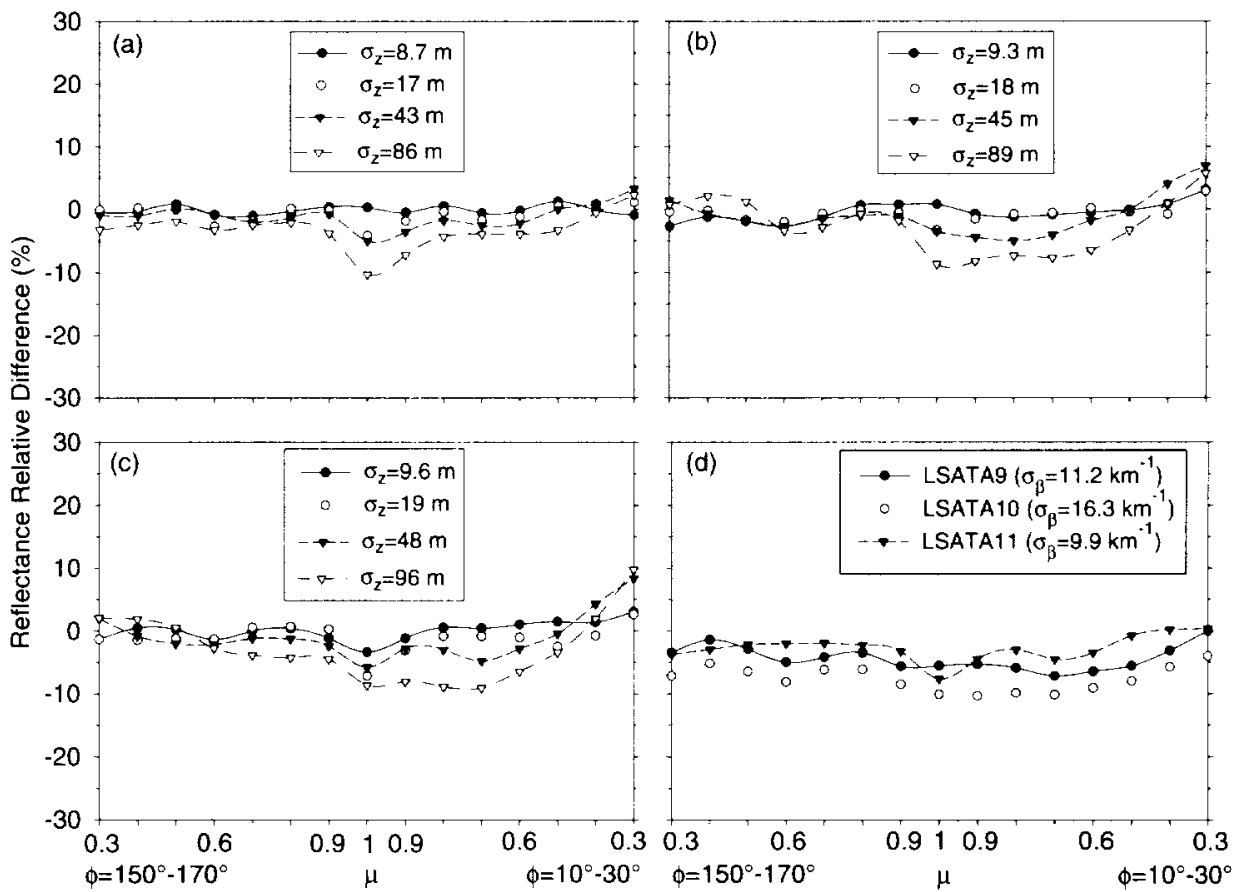

Fig. 7. Same as Fig. 6 but for $\tau_{t}=10$ and $\theta_{t,}=30^{\circ}$. 


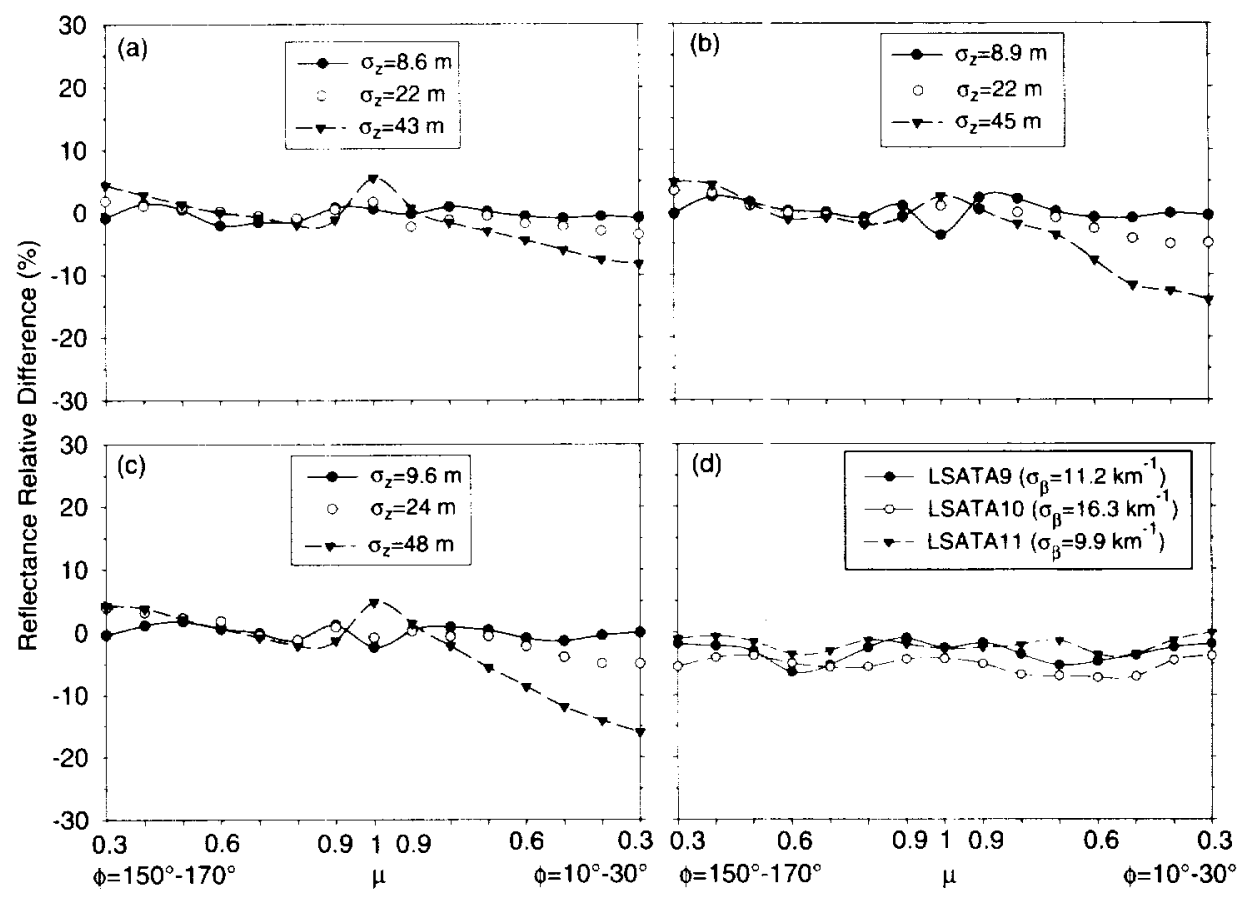

Fiti. 8. Same as Fig. 6 but for $\tau_{f}=5$ and $\theta_{t 1}=65^{\circ}$.

ference), whereas Figs. 9b and 9c show significantly larger deviations from 1D for the STOCHB_V2 and STOCHC_V2 cloud fields. Thus, large increases in cloud extinction variability in clouds with bumps can have a noticeable influence on cloud reflectance.

Reflectances from the cloud fields with bumpy tops deviate from 1D theory in a manner that is remarkably similar (qualitatively) to observed reflectances in LC98 (Figs. 9 and 10 in LC98). In that study, 1D reflectances increased much more rapidly with view angle than the observations in the forward-scattering direction, with relative differences reaching $\approx 20 \%$ at the most oblique view angles. In the backscattering direction, observed reflectances were much closer to $1 \mathrm{D}$ values at all view angles; relative differences were $\leqslant 10 \%$. Larger differences were also observed at low sun elevations. The remarkable similarities between the LC98 results and those in the present study suggests that cloud-top height inhomogeneities likely play a far greater role than cloud liquid water (or cloud extinction) variability in explaining the observed discrepancies in LC98.

\section{b. Photon order of scattering and cloud penetration depth}

To better understand the reason for the distinct angular pattern in the reflectance differences shown above and observed from satellite measurements (LC98), it is useful to examine distributions of the photon order of scattering and cloud penetration depth for photons exiting in different viewing geometries from $3 \mathrm{D}$ and $1 \mathrm{D}$ clouds. The order of scattering is defined as the number of scattering interactions a photon undergoes prior to leaving the cloud in a given direction. If a change in cloud-top structure affects the order of photon scattering distribut on, it will also influence reflectance.

Figures $10 \mathrm{a}$ and $10 \mathrm{~b}$ show the average number of photon satterings as a function of $\mu$ and $\sigma$, for the STOCHA and STOCHC cloud fields, respectively, in the forward-and backscattering directions (for $\tau_{d}=10$ and $\theta_{0}=65^{\circ}$ ). Also provided are the average number of photon scatterings for the plane-parallel model (1D). On average, photons exiting the cloud field in the nadir directior undergo $\approx 2.5$ times more scattering interactions thi $n$ those exiting at oblique $\mu$ in the forwardscattering direction. The order of photon scattering also decreases with view angle in the backscattering direction but not as rapidly. Figures $11 \mathrm{a}-\mathrm{d}$ show the correspondin $;$, frequency distributions for photons exiting in the nadi : direction (Figs. 11a,b) and in the $\mu=0.3$ $0.4, \phi==0^{\circ}-60^{\circ}$ direction (Figs. $11 \mathrm{c}, \mathrm{d}$ ). At nadir, the peaks ir the photon scattering distributions typically occur butween $\approx 8$ and 10 scattering events, and the distribut ons fall off relatively slowly at higher values. In contrist, photon scattering distributions at $\mu=0.3$ 0.4 are inuch narrower and peak after only $\approx 2-3$ scattering er ents. As illustrated in Fig. 12, which shows the average maximum depth within the cloud reached by photons prior to exiting (relative to $\bar{Z}=333.3 \mathrm{~m}$ ), photons leaving obliquely also tend to remain closer to the topmost portions of the cloud; that is, they generally remain above $\bar{Z}$, or stay within $\approx 25 \mathrm{~m}$ of that level, while photons exiting in the nadir direction typically pen- 


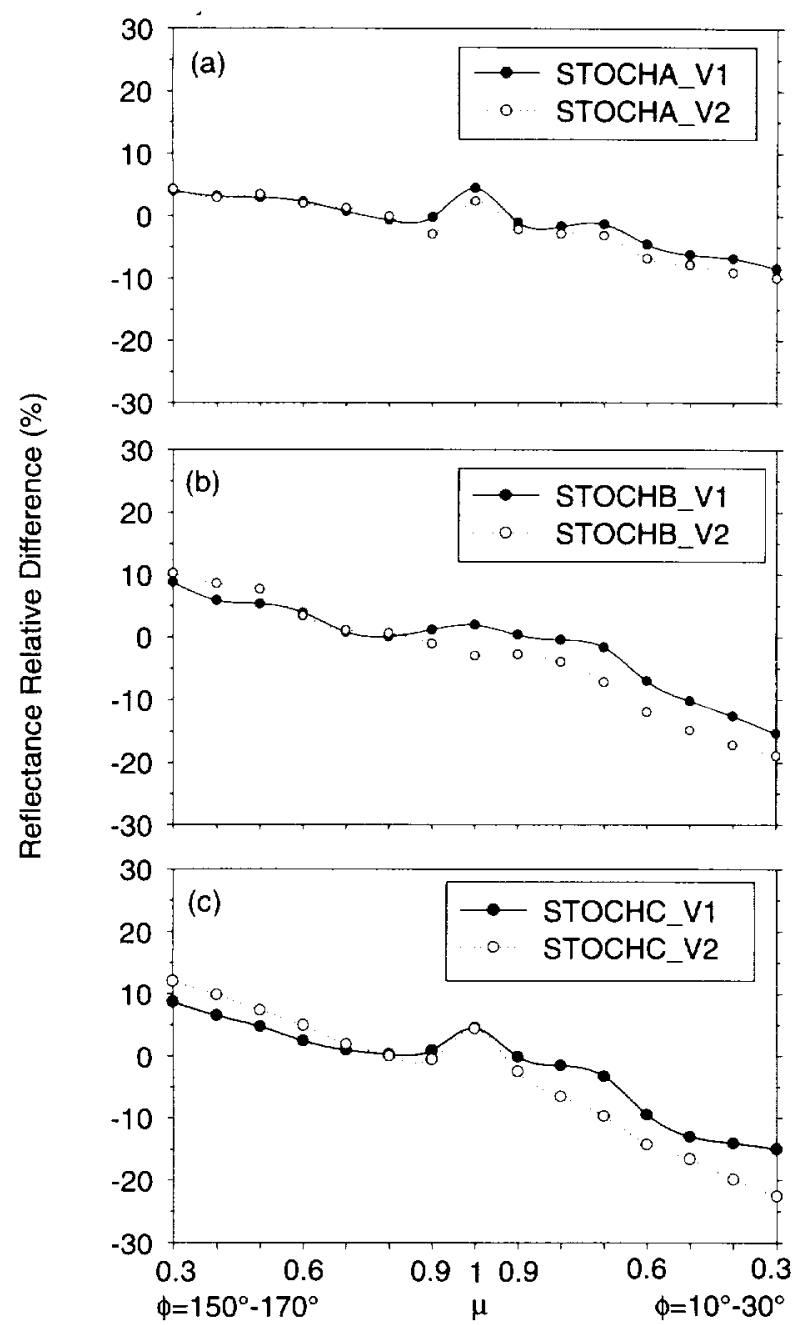

FIG. 9. Relative difference in reflectance between 3D cloud fields with cloud-top height and cloud extinction variations [section $2 \mathrm{~b}(3)]$ and plane-parallel calculations for optical depths based on (a) STOCHA, (b) STOCHB, and (c) STOCHC.

etrate $\approx 3-4$ times deeper (i.e., $\approx 75-100 \mathrm{~m}$ below $\bar{Z}$ ). Consequently, the reason $3 D-1 D$ reflectance differences are more sensitive to cloud-top height variations in the forward-scattering direction (at moderate to low sun elevations) is because as the view angle increases, the order of photon scattering decreases (i.e., photons experience fewer scattering events), and the scattering is restricted primarily to the topmost portions of the cloud. Thus, even small changes in cloud-top geometry have a direct effect on reflectances in that direction. At other viewing geometries (e.g., nadir view, backscattering direction), the order of photon scattering is larger and photons penetrate deeper into the cloud, thereby reducing the sensitivity to cloud-top geometry.

\section{c. Cloud-top geometry}

To further examine the relationship between reflectance deviations from 1D theory and cloud-top geom-

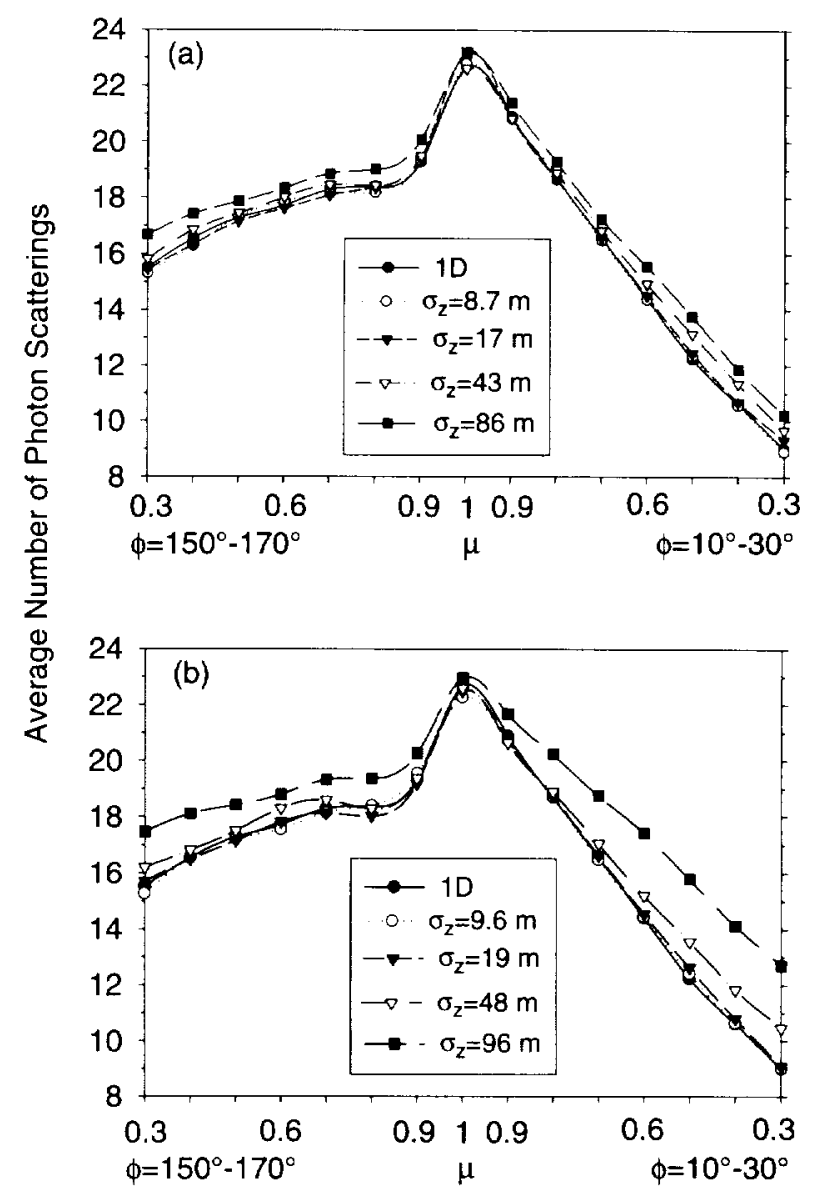

FIG. 10. Average number of scattering events undergone by photons prior to exiting the cloud field in the direction $(\mu, \phi)$ for $\theta_{11}=65^{\circ}$ and $\tau_{d}=10$ : (a) STOCHA. (b) STOCHC.

etry in the forward-scattering direction, relative reflectance differences in Figs. 6a-c were directly compared with the corresponding cloud properties summarized in Table 2. Remarkably, relative differences were found to depend linearly on the product of the average horizontal and vertical extent of the cloud bumps. To illustrate, Fig. 13 shows relative differences between reflectances from the variable cloud-top height fields and the planeparallel model at $\theta_{0}=65^{\circ}$ plotted against $\left\langle\tau_{1,}\right\rangle\left\langle\tau_{h_{1}}\right\rangle \cos \Theta$, where $\tau_{1}=\beta \bar{H}, \tau_{h}=\beta \bar{W}$, and $\cos \Theta$ is the cosine of the scattering angle $(\Theta)$. Included are all $\mu$ and $\phi$ for which $\cos \Theta \geq 0^{\circ}$, and all of the cloud fields in Table 2 are considered. As shown, relative reflectance differences increase (in magnitude) with $\left\langle\tau_{1}\right\rangle\left\langle\tau_{h}\right\rangle \cos \Theta$, with a correlation coefficient $(r)$ of 0.846 . Note that the $\cos \Theta$ factor accentuates the relative differences at small $\mu$, where they are largest.

Relative reflectance differences in the forward-scattering direction are larger for cloud fields with horizontally extensive cloud bumps because at low sun elevations photons must travel through longer horizontal pathlengths, and therefore experience more scattering 


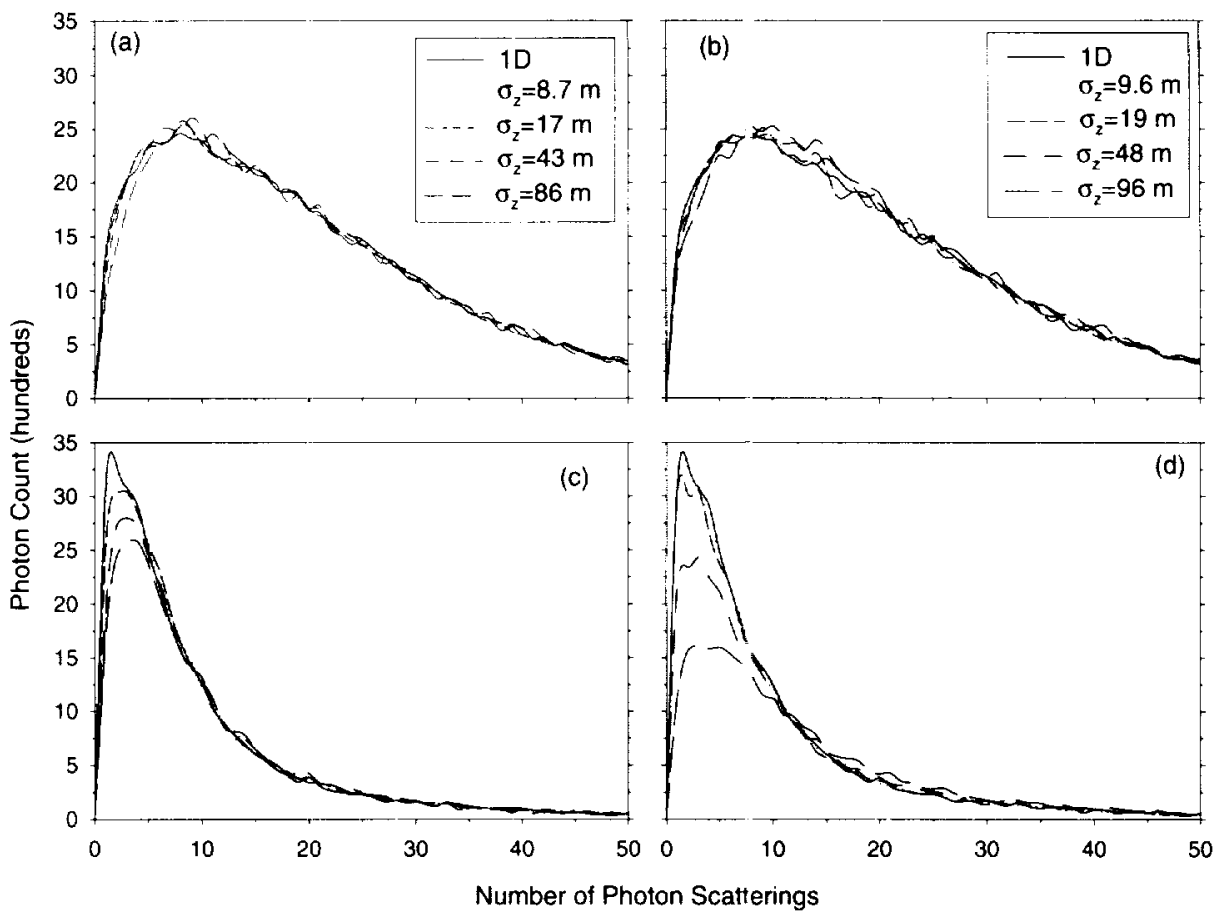

FiG. 11. Frequency distribution of the number of scattering eve ats undergone by photons prior to exiting the cloud in the nadir direction [(a) and (b)] and the $\mu=0.3-0.4 . \phi=0^{\circ}-60^{\circ}$ direction [(c) and (d)] for the STOCHA (left) and STOCHC (right) cloud fields for $\theta_{12}=15^{\circ}$ and $\tau_{d}=10$.

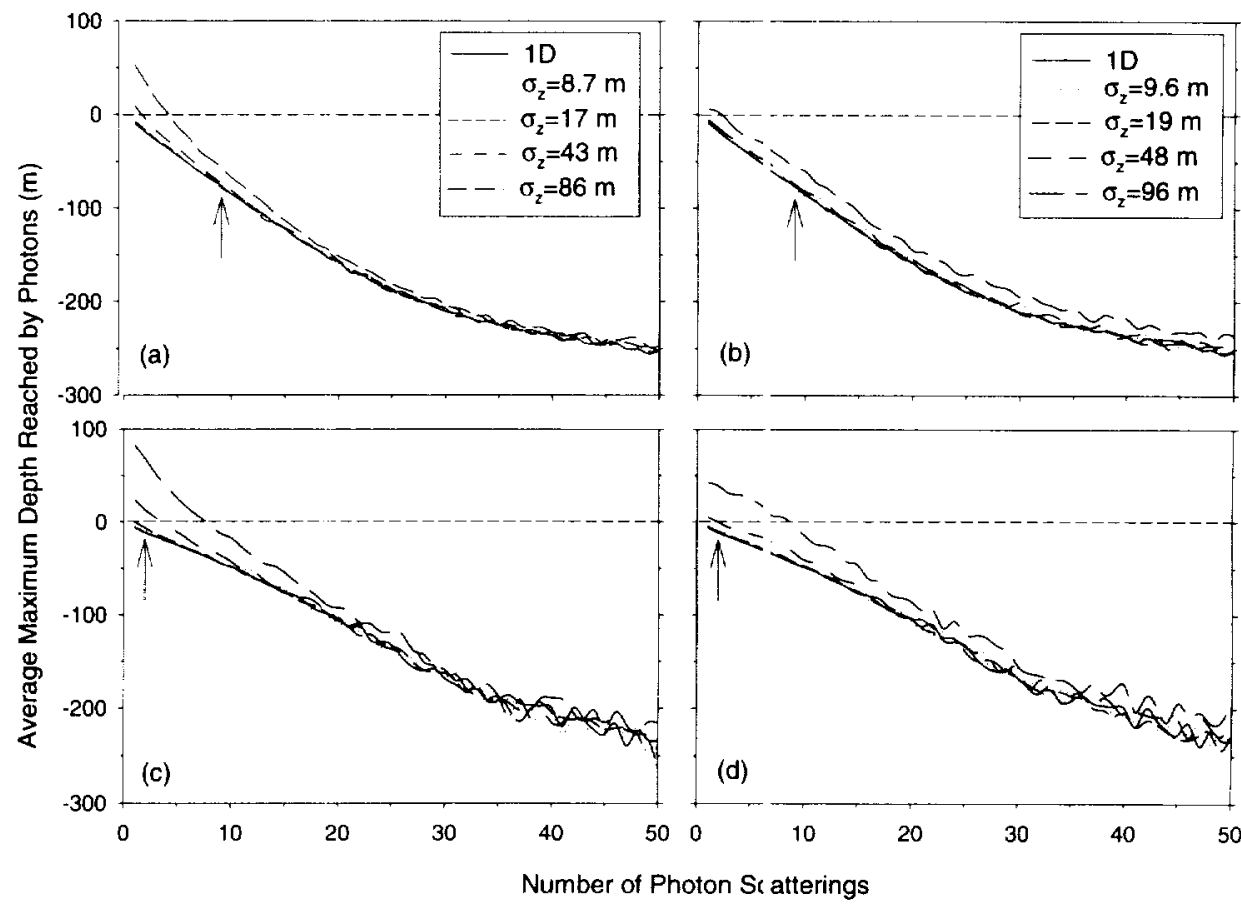

FiG. 12. Average maximum depth within cloud (relative to $\bar{Z}=333.3 \mathrm{~m}$ ) reached by photons prior to exiting the cloud field in the nadir direction $[(a)$ and $(b)]$ and if the $\mu=0.3-0.4, \phi=0^{\circ}-60^{\circ}$ direction [(e) and (d)] for the STOCHA (left) and STOCHC (right) cloud fields for $\theta_{i}=65^{\circ}$ and $\tau_{d}=10$. Arrows correspond to the approximate position of the peaks in the photen scattering distributions in Fig. 11. 


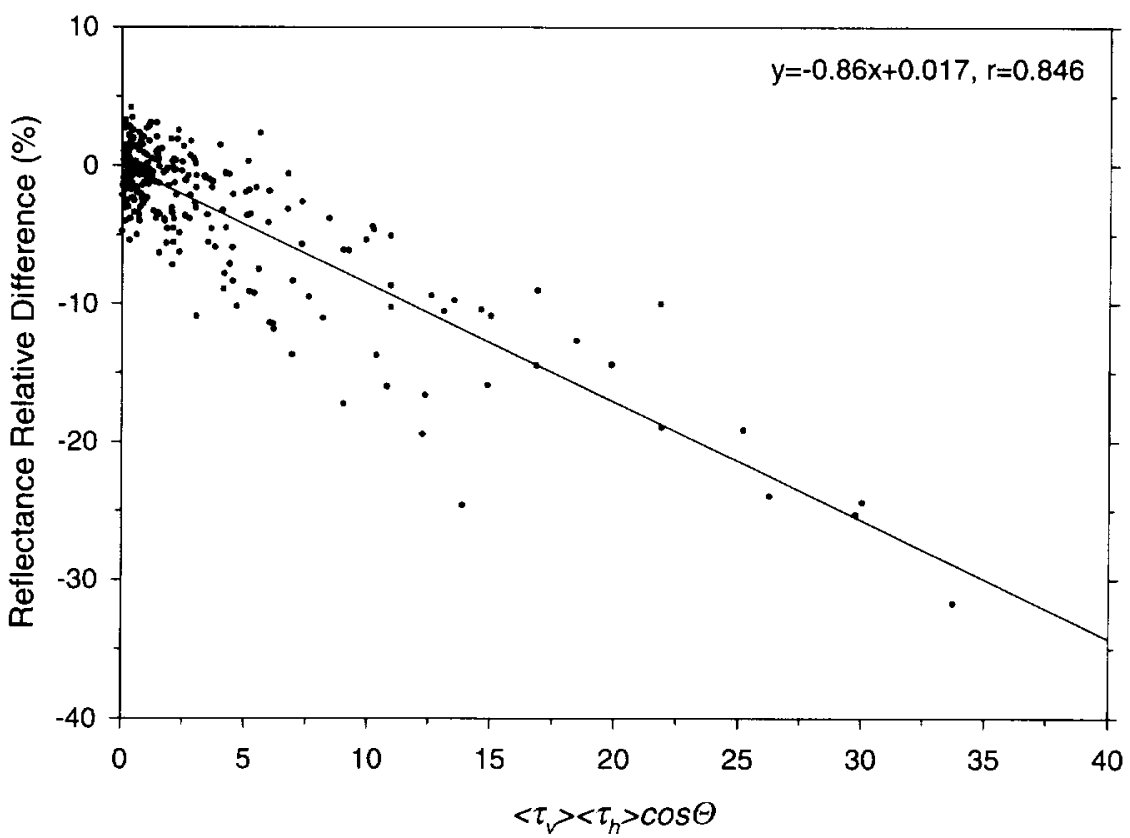

Fig. 13. Relative difference in reflectance against $\left\langle\tau_{n}\right\rangle\left\langle\tau_{n}\right\rangle \cos (-)$ for all variable cloud-top height cloud fields in Table 2 at $\theta_{\|}=65^{\circ}$ and $\tau_{d}=10$. Here. $\left\langle\tau_{v}\right\rangle=\overline{H \beta},\left\langle\tau_{b}\right\rangle=\overline{W \beta}$ wherc $\bar{\beta}=30$ $\mathrm{km}$. and $\Theta$ is the scattering angle.

events, in order to get through these bumps. An increase in the order of scattering means that photons have a greater likelihood of being redirected or scattered into other viewing directions, so the number of photons ex- iting obliquely into the forward direction decreases. To illustrate, Figs. 14a-d shows frequency distributions for the number of photon scatterings at very low sun $\left(\theta_{0}\right.$ $=80^{\circ}$ ), for photons exiting the cloud field in the nadir

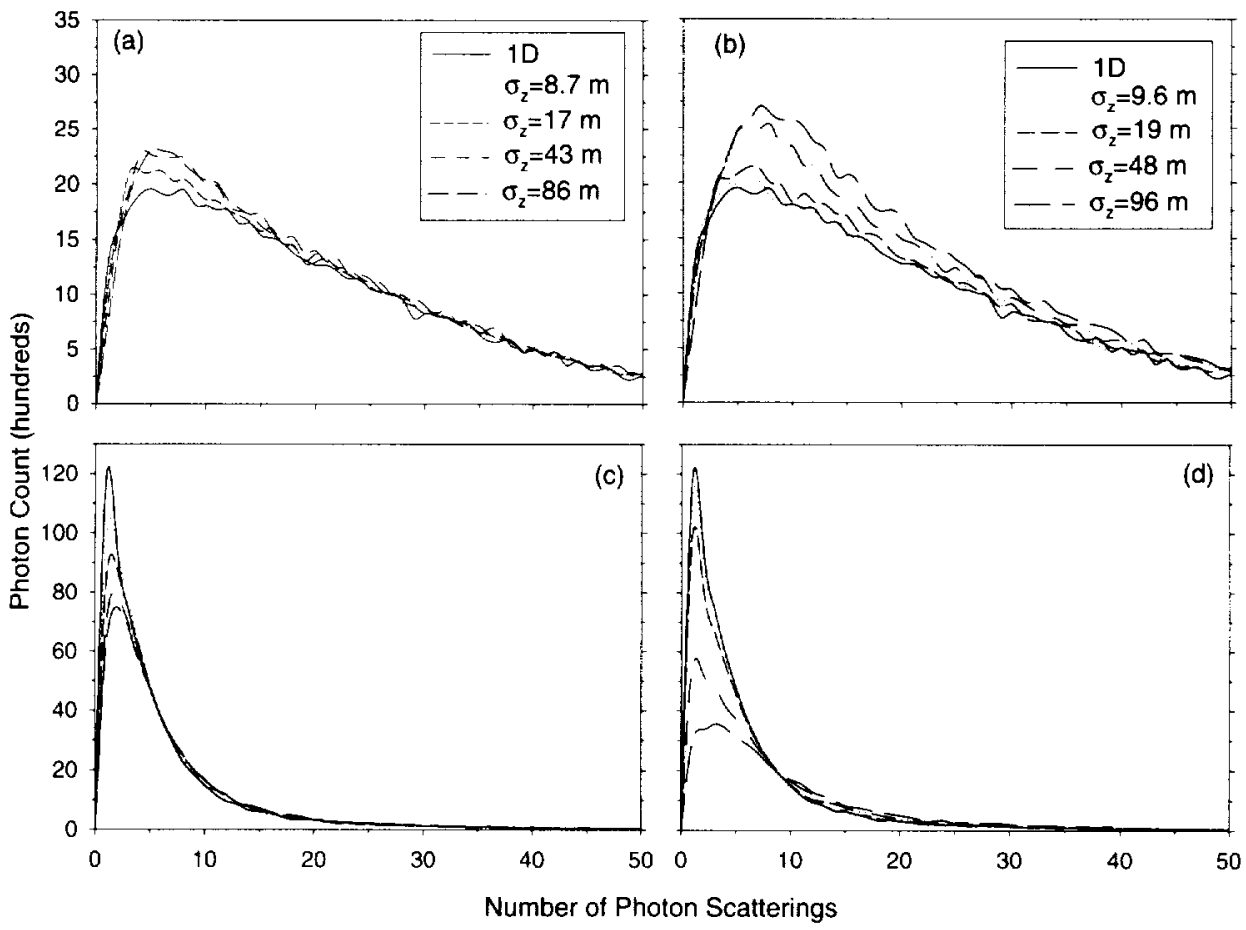

FIG. 14. Same as Fig. 11 but for $\theta_{11}=80^{\circ}$ and $\tau_{d}=10$. 


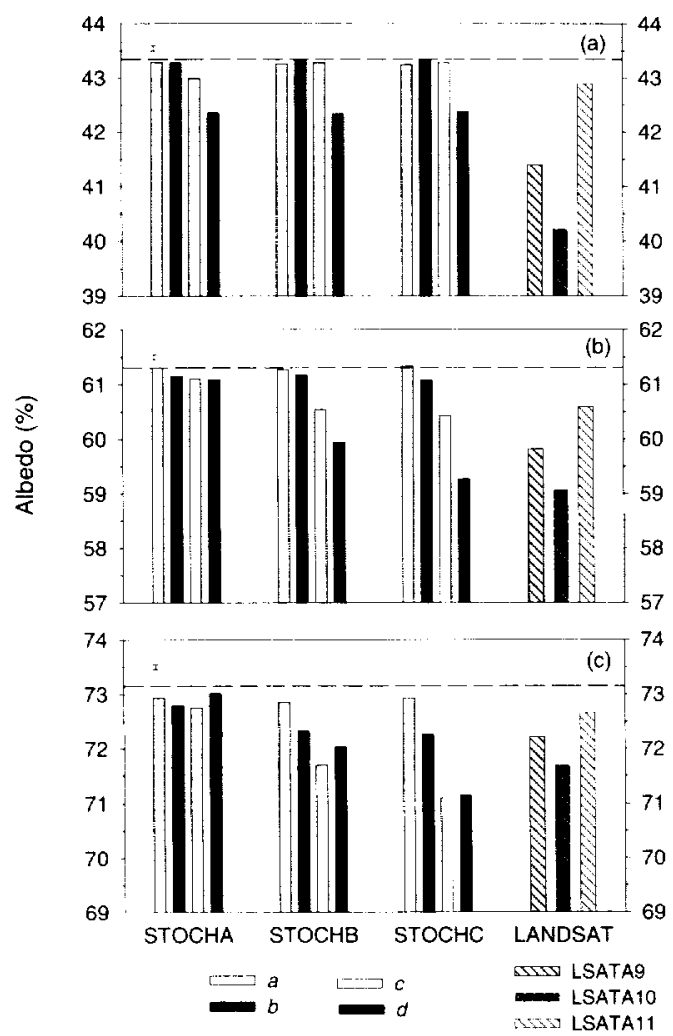

FIci. 15. Albedos for cloud fields with cloud-top height variations (STOCHA. STOCHB. and STOCHC) and variable cloud extinction (LSATA9. LSATA 10, and LSATA11) for $\tau_{1}=10$ at (a) $\theta_{1}=30^{\circ}$. (b) $\theta_{0}=65^{\circ}$, and (c) $\theta_{1}=80^{\circ}$. Dashed line represents the corresponding plane-parallel model values.

direction (Figs. 14a,b), and in the $\mu=0.3-0.4, \phi=$ $0^{\circ}-60^{\circ}$ direction (Figs. 14c,d), for the STOCHA and STOCHC cloud fields. As shown, there is sharp decrease in the number of photons exiting at $\mu=0.3-0.4$ as $\sigma_{\%}$, increases and a corresponding increase at nadir. These changes are most pronounced for the STOCHC case (Figs. 14b,d) because of the large horizontal extent of cloud bumps for this case. The increase in the number of photons exiting at nadir is consistent with what is observed in satellite measurements of reflectances (LC98; Loeb and Davies 1996) and in other 3D simulations (Loeb et al. 1997).

\section{d. Effect on cloud albedo}

To examine how inhomogeneities in cloud-top structure and cloud extinction affect cloud albedo at $\approx 4 \mathrm{~km}$ $\times 4 \mathrm{~km}$ scales, Figs. 15a-c show albedos for each of the cloud fields described in sections $2 b(1)$ and $2 b(2)$ for $\tau_{d}=10$ at $\theta_{0}=30^{\circ}$ (Fig. 15a), $65^{\circ}$ (Fig. 15b), and $80^{\circ}$ (Fig. 15c). The dashed lines represent the corresponding plane-parallel model albedos. For the variable cloud-top height fields, departures from 1D albedos increase with $\theta_{0}$, while the opposite is true for the flat clouds with only $\beta$ variations. The latter result is con- sistent $\mathrm{u}$ ith previous studies (Cahalan et al. 1994; Oeopoulous 1996; Barker et al. 1996). Interestingly, deviations from plane-parallel model albedos are comparable for these two types of cloud inhomogeneity. While deviations tend to be larger for the variable $\beta$ fields at high sur (reaching $\sim 7 \%$ for the LSATA 10 case at $\theta_{0}$ $=30^{\circ}$ ) (Fig. 15a), differences are typically $\leqslant 4 \%$ for all cloud fields at $\theta_{0}=65^{\circ}$ and $\theta_{0}=80^{\circ}$ (Figs. 15b,c). Given that reflectance deviations in section $3 \mathrm{a}$ were far greater for the bumpy cloud fields (Figs. 6a-d), this result is somewhat surprising. The reason for the different behavior is because reflectance deviations from $1 \mathrm{D}$ theory for the variable $\beta$ case are always negative (i.e., reflectances are always lower than $1 \mathrm{D}$ model values), regardless of viewing geometry (Figs. 6-8). Consequently, when these negative reflectance errors are integrated over all viewing geometries to give the overall albedo error, their cumulative effect can be appreciable. In contrast, reflectance differences for the variable cloud-top height fields are negative in the forwardscattering direction, but positive both at nadir (especially at low sun) and in the backscattering direction (althoug a the magnitude is smaller than in the forward direction). Consequently, errors cancel and the albedo bias is reduced for these cloud fields.

\section{Summary and conclusions}

Recent comparisons between observed reflectances and plare-parallel model calculations have shown that 1D theo $y$ fails to adequately represent the angular dependenc 3 in observed visible reflectance under certain conditio.s, even for extensive marine stratus layers (Loeb and Davies 1996; Loeb and Davies 1997; Loeb and Coakley 1998). Consequently, when ID models are used to infer cloud optical depths directly from satellite observations, the retrievals exhibit systematic shifts with changes in viewing geometry.

In the present study, Monte Carlo simulations comparing ID model reflectances with those from overcast $3 \mathrm{D}$ cloud fields were performed in order to show that the mair reason for the observed biases is likely because the plane-parallel model assumption does not account for subfixel-scale variations in cloud-top height (i.e., cloud bu mps). When cloud bumps are included in Monte Carlo si nulations, 3D reflectances deviate from $1 \mathrm{D}$ values with a view angle dependence that is remarkably similar 10 that obtained observationally. Specifically, 3D reflectar ces are smaller than $1 \mathrm{D}$ values in the forwardscatterir $\mathrm{g}$ direction (by as much as $\approx 30 \%$ at moderate to low : un and oblique view angles) but are similar in the baclsscattering direction. In contrast, when planeparallel model reflectances are compared with those from fla clouds with large horizontal variations in cloud extinction, no systematic view angle dependence in the differen :e is obtained, and relative differences remain $\leqslant 5 \%-1) \%$. Consequently, cloud-top height inhomogeneitie; likely play a far greater role than cloud liquid 
water (or cloud extinction) variability in explaining the systematic view angle dependent biases in satellite retrievals of cloud optical depth.

Reflectance deviations from 1D theory for clouds possessing both cloud-top height and cloud extinction variations are, however, found to be sensitive to large changes in cloud extinction. When cloud extinction is substantially increased in the cloud bumps (and decreased in the valleys between bumps), reflectance differences show a noticeable increase.

The reason reflectances for $3 \mathrm{D}$ clouds with bumpy tops deviate so much from $1 \mathrm{D}$ theory with changes in view angle in the forward-scattering direction is because the order of scattering is lower (particularly at oblique view angles), and photons generally remain close to the topmost portions of the cloud. As a result, 3D-1D relative reflectance differences are quite sensitive to changes in cloud-top geometry; in fact, they increase linearly (in magnitude) with increases in both the horizontal and vertical extent of the cloud bumps. At other viewing geometries (e.g., nadir view, backscattering direction), the order of photon scattering is larger and photons penetrate deeper into the cloud, thereby reducing the sensitivity to cloud-top geometry. While reflectance deviations from 1D theory are much larger for cloud fields with bumpy tops than flat clouds with variable cloud extinction, deviations in cloud albedo are shown to be comparable for these two cases.

These results, together with those presented in Loeb and Davies (1996) and Loeb and Coakley (1998), demonstrate that the common practice of using plane-parallel theory to retrieve cloud optical depth, even for clouds that are arguably plane parallel in appearance, is flawed and leads to significant biases. Since the biases tend to be less pronounced in the backscattering direction at solar zenith angles $\leqslant 60^{\circ}$, it is recommended that application of $1 \mathrm{D}$ theory be restricted to those angles.

Acknowledgments. The authors would like to thank Drs. H. W. Barker, B. A. Wielicki, and L. Parker for kindly providing their Landsat cloud optical depth retrievals, and Professor J. A. Coakley Jr. for his insightful comments and suggestions. This research was supported by NASA Grant NAG 11263.

\section{REFERENCES}

Barker, H. W. 1992: Solar radiative transfer for clouds possessing isotropic variable extinction coefficient. Quart. J. Rov. Meteor Sire., 118, 1145-1162.

- 1994: Solar radiative transfer for wind-sheared cumulus cloud fields. J. Atmos. Sci. 51, $1141 \ldots 1156$
— scale-invariant broken cloud fields. J. Atmos. Sci. 49, 11151126.

- , and,$- 1992 \mathrm{~b}$ : Cumulus cloud radiative properties and the characteristics of satellite radiance wavenumber spectra. Remote Sens. Environ., 42, 51-64.

- and D. Liu, 1995: Inferring cloud optical depths from Landsat data. J. Climate, 8, 2620-2630.

- B. A. Wielicki, and L. Parker, 1996: A parameterization for computing grid-averaged solar fluxes for inhomogeneous marine boundary layer clouds. Part II: Validation using satellite data. $J$. Atmos. Sci., 53, 2304-2316.

Boers, R., J. D. Spinhirne, and W. D. Hart, 1988: Lidar observations of the fine-scale variability of marine stratocumulus clouds. I. Appl. Meteor., 27, 797-810.

Cahalan, R. F., and J. B. Snider, 1989: Marine stratocumulus structure. Remote Sens. Environ., 28, 95-107.

—, W. Ridgway, W. J. Wiscombe, S. Gollmer, and Harshvardhan, 1994: Independent pixel and Monte Carlo estimates of stratocumulus albedo. J. Atmos. Sci., 51, 3776-3790.

Chambers, L. H., B. A. Wielicki, and K. F. Evans, 1997: On the accuracy of the independent pixel approximation for satellite estimates of oceanic boundary layer cloud optical depth. J. Geophis. Res. 102, 1779-1794.

Coakley, J. A., Jr., 1991: Reflectivities of uniform and broken layered clouds. Tellas, 43B, 420-433.

Davies, R., 1978: The effect of finite geometry on the three-dimensional transfer of solar irradiance in clouds. J. Amos. Sri. 35, $1712-1725$.

Divis, A., A. Marshak, R. F. Cahalan, and W. J. Wiscombe, 1997: The LANDSAT scale-break in stratocumulus as a three-dimensional radiative smoothing effect, implications for cloud remote sensing. J. Aimos. Sit., 54, 241-260.

Loeb. N. G., and R. Davies, 1996: Observational evidence of plane parallel model biases: Apparent dependence of cloud optical depth on solar zenith angle. J. Geophys. Re's., 101, 1621-1634.

, and - 1997: Angular dependence of observed reflectances: A comparison with plane parallel theory. J. Geophys. Res., 102, 6865-6881.

- and J. A. Coakley Jr., 1998: Inference of marine stratus cloud optical depths from satellite measurements: Does ID theory apply? I. Climate, 11, 215-233.

-. T. Varnai, and R. Davies, 1997: Effect of cloud inhomogeneities on the solar zenith angle dependence of nadir reflectance. $J$. Geophis. Res., 102, 9387-9395.

Marshak, A., A. Davis, W. J. Wiscombe, and R. F. Cahalan, 1995: Radiative smoothing in fractal clouds. I. Geophys. Res., 100, $26247-26261$.

Minnis, P.. P. W. Heck. D. F. Young. C. W. Fairall, and J. B. Snider, 1992: Stratocumulus cloud properties derived from simultaneous satellite and island-based instrumentation during FIRE. J. Appl. Meterr. 31, 317-339.

Oreopoulos, L., 1996: Plane parallel albedo bias from satellite mea surements. Ph.D. thesis, McGill University, $142 \mathrm{pp}$.

Várnai, T.. 1996: Reflection of solar radiation by inhomogeneous clouds. Ph.D. thesis, McGill University. 149 pp.

Welch, R. M.. and B. A. Wielicki, 1984: Stratocumulus cloud field reflected fluxes: The effect of cloud shape. J. Atmos. Sci. 41, $3085-3103$

- S. K. Cox, and J. M. Davis, 1980: Solar Radiation and Clonds. Meterr. Monogr., No. 39, Amer. Meteor. Soc., 96 pp.

Winker, D. M., R. H. Couch, and M. P. McCormick, 1996: An overview of LITE: NASA's Lidar In-space Technology Experiment. Proc. IEEE. 84, 164-180. 
